\title{
Crisis Perceptibility of People Requiring Assistance and Special Care: A Case Report
}

\author{
Dai Noguchi ${ }^{1^{*}}$ and Takashi Fujioka ${ }^{2}$ \\ ${ }^{1}$ Department of Human Sciences, University of Tsukuba, Ibaraki, Japan \\ ${ }^{2}$ Social Work Research Institute, Japan College of Social Work, Tokyo, Japan
}

"Corresponding author: Dai Noguchi, Junior Assistant Professor, Department of Human Sciences, University of Tsukuba, 1-1-1 Tennodai, Tsukuba, Ibaraki 305-8572, Japan, Tel: +81298536802; E-mail: dainoguchi@human.tsukuba.ac.jp

Rec date: October 24, 2017; Acc date: November 20, 2017; Pub date: November 22, 2017

Copyright: (c) 2017 Noguchi D, et al. This is an open-access article distributed under the terms of the creative commons attribution license, which permits unrestricted use, distribution, and reproduction in any medium, provided the original author and source are credited.

\begin{abstract}
A major problem during a disaster relates to people requiring assistance. Very few studies have investigated the difficulties people requiring assistance during an actual disaster experience. We examined the situations and behavior of those with intellectual, developmental, and psychiatric disorders during the Great East Japan Earthquake through semi-structured interviews of eight supporters. In essence, the study aimed to elucidate crisis perceptibility of people who require assistance and special care during disaster evacuation. Results revealed that immediately after the disaster occurred, people requiring assistance and special care during evacuation did not exhibit any signs of panic or unexpected reactions. We assumed that the factor that accounted for the finding was the presence of supporters who understood them. There was also the possibility that different cognitive function profiles of people requiring assistance and special care affected their behavior during a disaster.
\end{abstract}

Keywords: Crisis perceptibility; People requiring assistance and special care; Disaster; Evacuation

\section{Introduction}

The Great East Japan Earthquake on March 11, 2011 caused immense damage, particularly in East Japan. A major problem that occurs during a disaster is related to people requiring assistance during the disaster. These people, previously referred to as vulnerable people, are "those who need assistance with a series of evacuation behavior such as evacuating to a safe place in order to protect themselves from a disaster" and include the elderly, differently abled people, foreigners, infants, and pregnant women [1].

According to the White Paper on Disaster Management 2011 issued by Japan's Cabinet Office, people aged 60 years and over accounted for approximately $65 \%$ of the number of deaths caused by the Great East Japan Earthquake [2]. Similarly, the Japan Broadcasting Corporation (NHK) Fukushi Network (Welfare Network) reported that while the death rate of the total population was $1.03 \%$, the rate doubled to $2.06 \%$ for people with disabilities. Furthermore, a review of health care needs and relief activities literature following the Great East Japan Earthquake revealed that vulnerable groups particularly comprised the elderly, those suffering from psychiatric disorders, and differently abled people. The importance of incorporating this finding into future contingency plans was emphasized [3].

Subsequently, Iwata [4,5] investigated the sheltering behavior of patients suffering from dementia; priority was given to those who needed assistance during a disaster. Results showed that as dementia progressed, the sufferer no longer exhibited a fear reaction, even during a terrifying disaster. Rather, they remained calm and did not exhibit any spontaneous sheltering behavior. Furthermore, they could not recall the memory of their fear experience at all. Iwata referred to the symptom as lowered crisis perceptibility. This was also reported by staff in facilities for persons with developmental, intellectual, and chronic psychiatric disorders [4]. Assistance and special care in disaster evacuation are required for people whose impaired cognitive abilities render them unable to perceive a crisis; these include those with dementia, developmental and intellectual disabilities, and chronic psychiatric disabilities $[4,5]$.

The awareness and problems of people who need assistance during a disaster has been studied and researched by means of simulation during peaceful times [6]. Moreover, the governments devoted resources to develop programs and manuals after the Great East Japan Earthquake. However, very few studies have been conducted on the difficulties of people with cognitive impairment during an actual disaster, and lowered crisis perceptibility has not been considered in the guidelines.

Therefore, even among people requiring assistance, we defined those with cognitive impairment as people requiring assistance and special care in this study. Furthermore, to clarify the behavior of people requiring assistance and special care during a disaster, particularly those with intellectual, developmental, and psychiatric disorders, individual interviews were conducted with those who offered support during the Great East Japan Earthquake on March 11, 2011. In essence, we aimed to elucidate the crisis perceptibility of people requiring assistance and special care during disaster evacuation.

\section{Methods}

\section{Participants}

We conducted an interview with eight supporters who were involved in assisting the affected residents in City A (anonymous), particularly those requiring assistance and special care during a disaster, after the Great East Japan Earthquake on March 11, 2011. City A was affected by an earthquake, tsunami, and a nuclear disaster. We 
Page 2 of 3

intended to recruit participants in a similar condition and the snowball sampling technique was used to select participants, that is, participants nominated other people who were subsequently invited to participate.
Each participant was interviewed once; the interviews were conducted from December 2013 to January 2014. The characteristics of the participants are presented in Table 1.

\begin{tabular}{|c|c|c|c|}
\hline Participant (Gender) & Affiliation/occupation & $\begin{array}{l}\text { Location where participants } \\
\text { assisted }\end{array}$ & Supported person(s) \\
\hline A (Male) & Special needs education school/teacher & Special needs education school & $\begin{array}{c}\text { Children and students mainly with } \\
\text { developmental or intellectual disabilities }\end{array}$ \\
\hline B (Male) & $\begin{array}{l}\text { Social Welfare council of municipality/ } \\
\text { staff }\end{array}$ & Civic center & $\begin{array}{l}\text { Elderly people (including people with dementia), } \\
\text { children or persons with disabilities (intellectual, } \\
\text { physical, and mental disabilities), neighborhoods }\end{array}$ \\
\hline C (Female) & $\begin{array}{l}\text { Long-term care health facility/social } \\
\text { worker }\end{array}$ & Long-term care health facility & Elderly people (including people with dementia) \\
\hline D (Male) & Municipal health center/manager & Municipal health center & Elderly people, children, neighborhoods \\
\hline E (Female) & $\begin{array}{c}\text { Municipal health center/registered } \\
\text { dietitian }\end{array}$ & Municipal health center & Elderly people, children, neighborhoods \\
\hline $\mathrm{F}$ (Female) & $\begin{array}{c}\text { Municipal health center/public health } \\
\text { nurse }\end{array}$ & Municipal health center & Elderly people, children, neighborhoods \\
\hline G (Female) & $\begin{array}{c}\text { Senior citizen's welfare division of the } \\
\text { city/nurse }\end{array}$ & Municipal office & Elderly people, neighborhoods \\
\hline $\mathrm{H}$ (Male) & $\begin{array}{c}\text { Psychiatric hospital/medical social } \\
\text { worker }\end{array}$ & Psychiatric hospital & Mentally challenged people \\
\hline
\end{tabular}

Table 1:Characteristics of the participants.

\section{Interview}

After obtaining consent, we conducted semi-structured interviews. Each interview lasted between 50 and 80 minutes. The interviews were conducted at the participants' places of work. All interview data was recorded on a digital voice recorder.

\section{Content of the interviews}

The interviews focused on the situations and behavior of the people requiring assistance and special care during evacuation, particularly those with intellectual, developmental, and psychiatric disabilities.

\section{Analysis}

We processed the voice data of the interviews as verbatim proceedings and elaborately extracted all statements from the interview transcripts that were related to the study topic instead of categorizing the responses.

\section{Results and Discussion}

There were no observable signs of being in panic or unexpected behavior among the students of the special support education school, which included mainly individuals with developmental and intellectual disorders, and patients with psychiatric disorders and dementia; this information was conveyed by participants A, B, C, and $\mathrm{H}$. The support guidelines provided for people requiring assistance during a disaster in Japan [7] state that those with intellectual disorders, developmental disorders, and psychiatric disorders are likely to be in panic and act unexpectedly during a disaster. However, the results from the present study did not support the descriptions provided in these guidelines.
As mentioned previously, as dementia progresses, crisis perceptibility declines [5]. As a result, the person suffering from dementia no longer exhibits a fear reaction even during a terrifying disaster. Declined crisis perceptibility was also seen in those with developmental, intellectual, and chronic psychiatric disorders [4].

However, in contrast to previous findings, we did not obtain any reports about either panic or calmness in the interviews we conducted; this was evident in the interview with participant $\mathrm{A}, \mathrm{C}$, and $\mathrm{H}$. In the special needs education school, a girl would not leave her teacher and some children cried a little. In the psychiatric hospital, some patients were afraid and did not move. It was revealed that although they did not panic, their behavior appeared to be quite different.

One factor that may have accounted for this is that the people requiring assistance and special care had relatively mild cognitive function disabilities as indicated previously [5]. In fact, there were many children with mild disabilities in the school and only a few patients who had severe disorders in hospital. However, the degree of severity and characteristics of the disability may not be the only factors influencing the levels of crisis perceptibility. Different cognitive functions such as memory, judgment, and language may also affect crisis perceptibility. If different profiles of cognitive functions induce different behavior among people requiring assistance and special care during a disaster, they may fail to perceive a crisis and not evacuate, overly perceive a crisis and freeze, or panic. If this is the case, different responses by supporters, depending on the cognitive function profile of the person, would be necessary. Therefore, it is important to further investigate this possibility in detail.

In addition, during these interviews, it was revealed that in most cases people requiring assistance and special care were accompanied by supporters, teachers, or parents who understood them well; this was stated by participants A, B, and C. The presence of these supporters 
Page 3 of 3

may have prevented them from panicking. In contrast, different results could be expected if no people who understood them had been present.

In participant C's interview, she stated that people requiring assistance and special care were living in a shelter-like environment; namely, a long-term care health facility. Approximately 140 users and staff lived in a day room without electricity and water after the earthquake at this facility. According to the report, despite the fact that a number of people usually got agitated and uneasy and/or wandered around during peaceful times, there were no wanderers or agitators at the time. It appeared to be as though they had sensed the state of emergency. They were calm and seemed to understand the situation. They remained calm throughout the night and there were no cases of visibly worsened disorders.

However, participant $\mathrm{C}$ also reported that this long-term care health facility was able to allocate staff more thoroughly than usual following the disaster. As a result, the people requiring assistance and special care may have been able to stay calm. However, there were also some people with dementia who could not stay at a regular shelter. Consequently, these findings highlighted the importance of the presence of supporters.

Concerning the responses of supporters during evacuation following the Great East Japan Earthquake, we found that their responses were flexible and well accommodated in accordance with the given situation in participant A and E's interview. However, this on the other hand may imply that such calm responses were possible because the supporters underestimated tsunami warnings as indicated in participant $C$ and D's interview. For future evacuation when a major tsunami warning will be announced again, it is possible that supporters may lose their composure. For these reasons, as participant A stated, we presume that it is necessary for both people requiring assistance and supporters to engage and repeat training for various emergency cases.

\section{Limitation and Future study}

In this case study, we conducted semi-structured interviews with eight supporters in one city (City A) to arrange the conditions. However, eight supporters cannot represent one whole population. We have to examine in other affected areas. Moreover, we should also interview people requiring assistance and special care in a future study.

\section{Conclusion}

In terms of the conditions immediately after the occurrence of the disaster, people requiring assistance and special care during evacuation did not exhibit any signs of being in panic or acting unexpectedly. We assumed that the factor that accounted for this was the presence of supporters who understood them. Furthermore, the possibility exists that different cognitive function profiles of people requiring assistance and special care affect their behavior during a disaster.

\section{Ethical approval}

Ethical approval for this project was given by the research ethics committee of the Social Work Research Institute, Japan College of Social Work (receipt number: 13-0904).

\section{Acknowledgment}

Funding: This work was supported by the Health and Labour Sciences Research Grants [grant number: H24-Seishin-Shitei-001 (Hukkou)] from the Ministry of Health, Labour and Welfare of Japan.

\section{References}

1. Japanese Red Cross Society (2006) Guideline for people requiring assistance during the disaster (Saigaiji Youengosya Taisaku Guideline).

2. Cabinet Office (2011) White paper on disaster management 2011.

3. Ochi S, Murray V, Hodgson S (2013) The great East Japan earthquake disaster: A compilation of published literature on health needs and relief activities, March 2011-september 2012. PLoS Curr.

4. Iwata M (2012) Neurological features of decision-making deficit: Korinai syndrome in Parkinson disease and fearlessness in dementia. Brain Nerve 64: 1097-1102.

5. Iwata M (2011) New horizon of neuropsychological researches: Crisis perceptibility in dementia. Jpn J Neuropsychol 27: 189-195.

6. Femino M, Young S, Smith VC (2013) Hospital-based emergency preparedness: evacuation of the neonatal intensive care unit-the smallest and most vulnerable population. Pediatr Emerg Care 29: 107-113.

7. Miyagi Prefecture (2013) Miyagi prefecture guideline for supporters necessary for evacuation action. https:/www.pref.miyagi.jp/uploaded/ attachment/238323.pdf. 